\title{
Delayed-type drug hypersensitivity caused by paracetamol in a 2-year-old boy, confirmed by a positive patch test reaction and oral provocation
}

\author{
Liesbeth Gilissen ${ }^{1}$ (D), Sarien Mertens ${ }^{1}$, An Goossens ${ }^{1}$ (D), Dominique Bullens ${ }^{2}$ and \\ Marie-Anne Morren ${ }^{1}$ \\ ${ }^{1}$ Department of Dermatology, University Hospitals KU Leuven, 3000 Leuven, Belgium and 2 Department of Paediatrics, University Hospitals KU Leuven, 3000 \\ Leuven, Belgium
}

doi:10.1111/cod.12947

Key words: case report; drug hypersensitivity; maculopapular erythema; paracetamol; patch testing; provocation test.

Paracetamol (acetaminophen; $N$-acetyl-p-amino-phenol) is widely used as an antipyretic and analgesic drug. Immediate-type hypersensitivity reactions ranging from urticaria (1) to, exceptionally, anaphylactic shock (2) are well known by physicians, but reported cases of delayed-type hypersensitivity reactions are relatively rare $(3-5)$.

\section{Case Report}

An 18-month-old boy was referred to the dermatology department of our university hospital by a paediatrician in December 2015 because of facial oedema and maculopapular erythema (MPE) following administration of a paracetamol-containing suppository (Perdolan ${ }^{\circledR}$ baby; Janssen Pharmaceutica, Beerse, Belgium) for the treatment of fever. His parents reported three previous such episodes, described as an itchy rash, starting at one particular site on the neck $\sim 6 \mathrm{~h}$ after use of the drug, spreading to the upper part of the chest, and later followed by desquamation of the skin during the following days, resolving after $\sim 1$ week. The boy did not have a personal history of atopic eczema, asthma, or hay fever; however, relatives of the mother suffered from atopic eczema. No other intolerances were noted. At the time of consultation, the differential diagnosis consisted of an infectious rash, drug eruption, or a fixed drug eruption.

In February 2016, patch tests with the topical products that the patient had been using were performed 'as is', together with most of their ingredients, by the use of

Correspondence: Dr. Marie-Anne Morren, Department of Dermatology, University Hospitals KU Leuven, Kapucijnenvoer 33, B-3000 Leuven, Belgium. Email: marie-anne.morren@uzleuven.be

Conflict of interest: All authors declare no conflict of interest.
IQ patch test chambers ${ }^{\circledR}$ (Chemotechnique Diagnostics, Vellinge, Sweden) fixed with Mefix ${ }^{\circledR}$ (Mölnlycke Health Care, Göteborg, Sweden) on the patient's back. Paracetamol was tested at $10 \%$ pet. (Chemotechnique Diagnostic) on the back, and also on the previously affected area on the neck. The patch test readings were performed according to the guidelines of the European Society of Contact Dermatitis on day (D) 2 and D4 (6). Only the patch test with paracetamol on the neck showed a positive reaction, in terms of infiltration and redness (+) on D2, and infiltration and desquamation (+) on D4 (Fig. 1); all other tests, including with paracetamol, gave negative results.

In June 2016, graded oral provocation testing with paracetamol (up to a 200-mg dose, i.e. a cumulative dose of $30 \mathrm{mg} / \mathrm{kg}$; Algostase Mono ${ }^{\circledR}$; Laboratoires SMB, Brussels, Belgium) was performed at the department of paediatrics between 10 a.m. and 1 p.m. Five hours later, there was no reaction, and the boy was allowed to leave the hospital; however, $\sim 8 \mathrm{~h}$ after administration, the parents

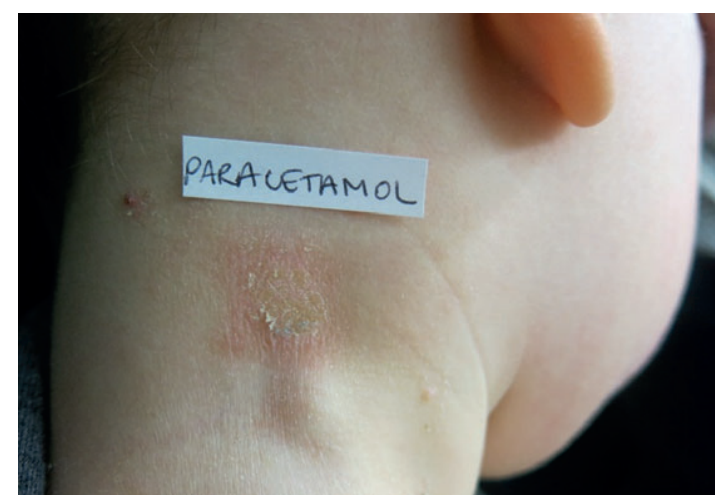

Fig. 1. Positive patch test reaction on day 4 to paracetamol $10 \%$ pet. 
noticed a widespread MPE, including on the particular site on the neck, for which the parents had to consult the emergency unit, where treatment with an oral corticosteroid was started. Thereafter, the parents were told to avoid the use of paracetamol. In July, they gave the boy ibuprofen (preparation adapted by the pharmacist) for the treatment of a sunburn, which he tolerated well.

\section{Discussion}

Both patch testing and oral provocation testing identified paracetamol as the culprit agent in all episodes, emphasizing the value of patch testing as an initial diagnosti technique for delayed-type drug hypersensitivity reactions (7), especially in those cases in which the risk of more severe generalized reactions is high. Moreover, the present case shows the importance of patch testing, preferably on the previously most affected site (8). It remains unclear why the patient only reacted positively on the initially affected site, that is, the neck, and not on the back, where he had also had the skin eruption.

In the database developed in-house at our contact allergy unit, containing data on patch test results of $\sim 22000$ patients tested since 1978, only 1 other patient of 189 tested with paracetamol showed a delayed positive patch test reaction like the present patient.

\section{Acknowledgements}

We would like to thank the Clinical Research Fund of the University Hospitals Leuven (Klinische onderzoeksen opleidingsraad KOOR) for supporting this research work.

\section{References}

1 Blanca-López N, Cornejo-García J A, Pérez-Alzate D et al. Hypersensitivity reactions to nonsteroidal anti-inflammatory drugs in children and adolescents: selective reactions. J Investig Allergol Clin Immunol 2015: 25: 385-395.

2 Couto M, Gaspar A, Morais-Almeida M. Selective anaphylaxis to paracetamol in a child. Eur Ann Allergy Clin Immunol 2012: 44: 163-166.

3 Irion R, Gall H, Werfel T, Peter R U. Delayed-type hypersensitivity rash from paracetamol. Contact Dermatitis 2000: 43 $60-61$.
4 Rojas-Pérez-Ezquerra P, Sánchez-Morillas L, Gómez-Traseira C et al. Selective hypersensitivity reactions to acetaminophen: a 13-case series. J Allergy Clin Immunol Pract 2014: 2: 343-345.

5 Ibanez M D, Alonso E, Muñoz M C et al. Delayed hypersensitivity reaction to paracetamol (acetaminophen). Allergy 1996: 51: 121-123.

6 Johansen J D, Aalto-Korte K, Agner T et al. European Society of Contact Dermatitis guideline for diagnostic patch testing - recommendations on best practice. Contact Dermatitis 2015: 73: 195-221.

7 Barbaud A, Reichert-Penetrat S, Tréchot P et al. The use of skin testing in the investigation of cutaneous adverse drug reactions. Br J Dermatol 1998: 139 : 49-58.

8 Barbaud A, Trechot P, Reichert-Penetrat S. The usefulness of patch testing on the previously most severely affected site in a cutaneous adverse drug reaction to tetrazepam. Contact Dermatitis 2001: 44: $259-260$. 